Revista Iberoamericana, Vol. LXVIII, Núm. 200, Julio-Septiembre 2002, 639-643

\title{
EN TORNO A VALLEJO
}

POR

Carlos Germán Belli

Si César Vallejo resucitara entre nosotros, seguramente una mayúscula sorpresa se llevaría, al verse exaltado, en virtud de su verbo poético, en una suerte de santón o anunciador de la buena nueva, ya no para los pueblos hispanos, sino aun para toda la especie humana. Pero lo curioso es que él jamás tuvo en mente ni siquiera ser el gonfalero de su generación en su país natal, ni menos jefe de escuela literaria alguna y mucho menos un clarividente guía para los hombres de este siglo.

Efectivamente, según podemos desprender de los hechos de su existencia, Vallejo es el escritor menos indicado como para suponer en él la figura de un conductor literario, pues aparentemente — salvo alguna que otra nota periodística— no demostró interés en ello, ni ostentó ningún rasgo caracterizador de este tipo de escritores. Si bien el poeta peruano, en su juventud, declaró durante una velada que algún día sería tan famoso como Rubén Darío —invariablemente maestro de él y espíritu fraterno en lo psicológico—, sin embargo se diferencia del nicaragüense, porque quizá nunca se sintió conscientemente un reformador o adalid de las letras castellanas de su tiempo, como ocurría con el autor de Azul ... quien sí con plena convicción ejerció tal papel, a partir de dicho libro y a la muerte de los premodernistas, y, por añadidura, no obstante de su inveterada timidez, que le imposibilitaba toda comunicación, que no fuera la poesía.

Por otra parte —es redundante decirlo — a diferencia del merecidamente exitoso nicaragüense, el peruano discurrió rígidamente sus días más bien por el lado opaco de la existencia, es decir, como el común de los mortales — por cierto, con los vaivenes típicos de cualquier escritor latinoamericano en Europa-, y muy lentamente vio en vida difundirse su obra que, breve en sí, sólo se duplicó en sus postreros días, ya en trance de muerte. En este punto, cabría observar que su toma de contacto con el mundo literario español de entonces, no tendrá lógicamente los ribetes que caracterizaron la entronización de Darío o de algunos otros modernistas, quienes fueron recibidos con un pleno reconocimiento por parte de sus colegas hispanos, sellado todo con ceremonias públicas, veladas fraternas o inolvidables anécdotas. En cambio, Vallejo hace su ingreso al viejo solar hispano, primero casi subrepticiamente, yendo a Madrid a cobrar periódicamente el estipendio de una beca que el gobierno español le había otorgado; posteriormente traba amistad con algunos escritores como Larrea, Bergamín y Diego, y por iniciativa de estos dos últimos se reedita Trilce, con prólogo de aquél y poema luminar de éste. 
Por otra parte, si no se esbozan en Vallejo los rasgos del clásico capitán literario, menos lucirá, como es de suponer, aquello que tipifica a los vigías espirituales de todas las épocas. Aunque a partir de 1929, luego de una crisis anímica —según sus biógrafosVallejo abraza el marxismo, se adhiere al partido comunista español e inclusive llega a ejercer con especial fervor el papel de modesto adoctrinador en los tumultuosos días de la Guerra Civil Española, el poeta peruano no sale sin embargo de este bautizo político, como en el caso de su contemporáneo Pablo Neruda, con la asunción de la estética realista, basada en una poesía sencilla para hombres sencillos, fórmula a la que rotundamente aspiró el chileno al dar las espaldas, en particular a sus sibilinas dos primeras Residencias, que no obstante siguen siendo tan admiradas por muchos. Por su parte, Vallejo más bien amplía su ya subyacente solidaridad humana, su conmiseración consigo y con los demás, y redondea así el espíritu total de su musa. Pero, si bien militante y autor de libros de índole sociológica, en realidad no es el poeta que escribe conforme a las normas del llamado realismo socialista.

Pues bien, este escritor que hoy en día es exaltado como una suerte de varón arquetipo, para la gente del siglo, por parte de tirios y troyanos, sólo pretendió ser en vida un simple artista, que se afanó como todo poeta de verdad en subvertir su idioma, en alcanzar una escritura propia y auténticamente nueva: allí está la carta a su amigo y prologuista Antenor Orrego, a raíz de la poca resonancia de Trilce, o su escrito sobre lo que debe ser la poesía vanguardista, en base más bien en un veraz espíritu renovador, y no en un gratuito verbalismo ensamblado únicamente por palabras propias de la vida moderna. Así, pues, por sobre todo creador, y seguramente inclusive en el largo ostracismo literario, que le sobrevino en su permanencia en París; y no podía ser de otro modo, ya que el verbo poético se había encarnado en él con tal grande fuerza y en tales particulares circunstancias, que quizás pocos de los grandes creadores contemporáneos pueden haber pasado por ellas. Este escritor labra su lenguaje en el seno de un continente de más o menos incipiente tradición literaria, y más aún en dos ciudades sudamericanas olvidadas de Dios una más que otra, y en donde el ejercicio del desdén étnico, económico o regional es una de las mayores obsesiones colectivas. En este duro escenario, más remoto por cierto hace medio siglo, Vallejo transcurre su existencia hasta alcanzar la treintena de edad; pasa allí su juventud que verá marcada por un injusto encarcelamiento; discurre mayormente entre Trujillo y Lima, y su vida sentimental se irá configurando — como la mayoría de los muchachos hispanoamericanos- de frustración en frustración, hasta llevarlo a una concepción dolorosa del amor, en que fusiona la mística y la erótica, a la manera de sus antecesores inmediatos Herrera y Reissig y Darío. En fin, siempre nos hemos imaginado a Vallejo joven, por las viejas calles del centro comercial limeño, caminando altivo, cuidadoso en el vestir — porque todo joven poeta es un dandy por naturaleza, según nos dice Borges en uno de sus últimos poemas-; pero repentinamente, como buen sensitivo que es, terminando por dirigir sus pasos hacia el siniestro Barrio Chino, tal vez para borrar de su mente la clásica sonrisita limeña que le hería en el alma como un estilete, y que jamás pudo olvidar, según sabemos.

Pese a todo ello, el escritor peruano se dio mañas para redactar primero Los heraldos negros, de resonancias aún postmodernistas, y con el cual sentó convenientemente las 
bases de su universo poético; y luego su vanguardista Trilce, publicado en 1922, y del cual todavía se persiste en detectar influencias del surrealismo, a pesar de que esta escuela nació formalmente dos años después, con la aparición del primer manifiesto de André Breton, como acertadamente nos ha hecho ya ver Roberto Fernández Retamar. ${ }^{1}$ No obstante su enclaustramiento limeño, es casi seguro que Vallejo estaba enterado de los otros movimientos de vanguardia que habían comenzado a aparecer en Europa a partir de 1911; y de allí asimiló ese "aire de tiempo" que conforme él anhelaba como lo expresó en un artículo, no quedó como tal cosa, sino que comenzó a circular por sus moradas modernistas y su adolorida psiquis, quedando como secuela los complejos versos de su segundo libro.

En este punto debemos señalar las relaciones vallejianas con el surrealismo, así como el punto de vista de uno de sus miembros con respecto a él. En vez de mostrar interés o simpatía, Vallejo se unirá más bien al coro de los enemigos o disidentes, al escribir en 1930 su “Autopsia del superrealismo"2 que, como señala André Coyné, ${ }^{3}$ es una pieza más de esa serie de necrología literaria en boga por aquellos días, que solía publicarse contra el inquietante movimiento; con esta dura admonición, el poeta sudamericano sellaba definitivamente sus discrepancias y cerraba los caminos a cualquier posible acercamiento con sus colegas surrealistas. Pero la renuencia es matemáticamente recíproca, y ésta se hace patente en la opinión de César Moro —el poeta peruano militante del surrealismoquien, según tenemos conocimiento, no gustaba de los versos vallejianos, y en cambio se declaraba fervoroso partidario del simbolista José María Eguren.

Esta honda discrepancia nos hace comprender el fenómeno poético hispanoamericano a partir de 1940 a la fecha, y tal vez vislumbrar las resonancias extremas del autor de Poemas humanos. En el curso de las tres últimas décadas, como se sabe, las figuras tutelares han sido Vallejo y Neruda, pero frente a ellos se alcanza a distinguir el incandescente surrealismo, que no obstante el rechazo lapidario de los dos grandes poetas, no deja de extender sus fulgores primeramente como por control remoto, tal como puede apreciarse en Chile, donde surge el activo grupo Mandrágora, que publica la revista del mismo nombre y protagoniza legendarios episodios; y poco después en México con la propia presencia de Breton y de otros miembros del movimiento. En suma, la influencia nerudiana y vallejiana fue avasalladora en las dos primeras décadas, durante cuyo lapso sólo quedan diseminados en la floresta poética hispanoamericana algunos cuantos francotiradores aferrados inalterablemente a su fe en la superrealidad o en el purismo literario, en espera de mejores tiempos para ellos. Pero las cosas comenzaron a cambiar en el pasado decenio, con la aparición de nuevas personalidades influyentes y una visible voluntad de

\footnotetext{
1 "Para leer a Vallejo". Prólogo a César Vallejo, Poesías completas (La Habana. Casa de las Américas, 1965). Reproducido en R.F.R., Ensayo de otro mundo (Santiago de Chile: Editorial Universitaria, 1969) 82-92.

2 Publicado en Variedades, de Lima, No. 1151 (26 de marzo de 1930) y reproducido en Nosotros, de Buenos Aires, No. 250 (marzo de 1930) y Amauta, de Lima (30 de abril/mayo, 1930).

3 “César Vallejo, vida y obra”, en Homenaje Internacional a César Vallejo”, Visión del Perú, № 4 (julio de 1969) 44-57. Véase al respecto, Juan Larrea, “César Vallejo frente a André Bretón”, en Revista de la Universidad Nacional de Córdoba, Argentina, No. 3-1 (1969) [Hay separata] y el artículo de Coyné en este $\mathrm{N}^{\circ}$ de la $R I$.
} 
asimilación de los rasgos fundamentales del surrealismo y de la poesía moderna en general, por parte de las nuevas generaciones, sea por vía directa o por vía interpósita.

Diferentemente de lo que ocurrió en Chile con Neruda, donde las generaciones posteriores a él se vieron en la perentoria necesidad de cerrar rápidamente filas ante el torrente lopesco de sus versos; en el Perú, con Vallejo en cambio, la gravitación de éste ha sido notoria en particular en la generación del medio siglo, aunque habría que indicar de paso que la adhesión, en muchos casos, fue sólo a una porción de su espíritu -lo social con exclusión de lo metafísico—, y por lo demás casi nunca en su forma poética, en razón de ser por cierto un modelo difícil de imitar, a diferencia del propio Neruda o de los grandes maestros modernistas del pasado. Tal situación se modificará ostensiblemente con el advenimiento de la hornada siguiente, quienes sin dejarse avasallar por la lícita indignación que les provoca la realidad social tremendamente injusta — salvo el caso ya legendario de Javier Heraud-, dan la impresión de un afán de incorporarse plenamente a la gran tradición de la revolución poética moderna, y para ello vuelcan sus intereses concretamente hacia la poesía de habla inglesa o en los nuevos influyentes poetas hispaoamericanos.

Sin embargo, Vallejo está más vivo que nunca en Hispanoamérica; sea porque prosigue ganando sus batallas literarias después de muerto, sea porque los alcances de su voz superan el dominio específicamente poético, según el consenso casi general. Así, pues, uno de sus últimos exégetas, Mario Benedetti, señala que Vallejo por sobre todo es un "paradigma humano", ${ }^{4}$ en tanto que Neruda es el "paradigma literario” por excelencia; y en tal condición — según el escritor uruguayo - Vallejo vendría a ser una suerte de cabeza de tribu, con quien está entroncado, por diversas vías y grados, un gran sector de los poetas hispanoamericanos que hoy pasa de los cuarenta años de edad. Pero hay otros devotos de Vallejo que van aún más allá de lo señalado por Benedetti, cuya cala en última instancia estaba ceñida al ámbito del hombre de letras-lector; en efecto, el monje y poeta norteamericano, Thomas Merton, trágicamente fallecido no hace mucho, se convierte en el más fervoroso vallejiano de los últimos tiempos, al darle las palmas de la universalidad entre todos los poetas modernos, y señalando además que la traducción de los versos del hispanoamericano es "un proyecto de muy grande y urgente importancia para toda la raza humana". ${ }^{5}$

¿Qué diría entonces nuestro poeta al verse hoy ungido como un profeta de los tiempos modernos, él que siempre iba a la zaga de la grey humana? La universalidad que Merton le señala —al igual que desde el primer momento Juan Larrea-, en honor a la verdad el autor de Trilce la alcanzó así por añadidura, en un dejarse llevar por la corriente de sus más recónditos sentimientos; no buscó el punto equidistante de los contrarios en su alrededor, por no tener en realidad necesidad de hacerlo, ya que la clave estaba “aquicito nomás” como suelen decir sus paisanos humildes - es decir, en el linaje de su sangre y su espíritu, y de cuyo seno salieron tantos versos de disolución antinómica, como nos lo ha hecho

\footnotetext{
${ }^{4}$ Letras del continente mestizo (Montevideo: Editorial Arce, 1967), artículo titulado "Vallejo y Neruda: dos modos de influir".

${ }^{5}$ Thomas Merton, “César Vallejo”, en Emblems of a Season of Fury (Norfolk, Connecticut, a New Directions Paperback, 1963) 135-140.
} 
apreciar lúcidamente Larrea; ${ }^{6}$ todo ello tenía que conducirlo naturalmente a casar en su ser actitudes tan irreductibles: primero la liturgia y la erótica en los días de su frustrada juventud, y luego en la edad madura el cristianismo y el marxismo.

Pero, en fin, la vida una vez más nos da, de modo desconcertante, su lección: su misterioso sentido se rebela a todo esquema que puedan crear los hombres: Vallejo, quien vivió según se dice a espaldas de lo maravilloso, del amar loco, del azar objetivo, del humor negro, y que tal vez nunca pensó conscientemente en la disolución de las fronteras antinómicas, él, con su vida y su obra inusitadas, es la más alta encarnación en la literatura contemporánea, del justo anhelo de los surrealistas, a quienes paradójicamente se apresuró a extenderles en forma prematura la correspondiente partida de defunción.

Volumen XXXVI

Abril-Junio 1970

Número 71

\footnotetext{
${ }^{6}$ Juan Larrea, César Vallejo o Hispanoamérica en la cruz de su razón (Universidad Nacional de Córdoba, Argentina. Publicaciones del Centro de Estudiantes de Filosofía y Letras, 1957).
} 